\title{
Preparation of Composite Particles by Forming Pickering Emulsion Followed by Drying-In-Liquid and Effect of Stepwise Addition of Solid Powder on Structure of Composite Particles
}

\author{
Yasushi Akutsu, Yoshinari Taguchi, Masato Tanaka* \\ Graduate School of Science and Technology, Niigata University, Niigata, Japan. \\ Email: *tanaka@eng.niigata-u.ac.jp \\ Received October 10, 2013; revised November 13, 2013; accepted November 26, 2013 \\ Copyright (C) 2013 Yasushi Akutsu et al. This is an open access article distributed under the Creative Commons Attribution License, \\ which permits unrestricted use, distribution, and reproduction in any medium, provided the original work is properly cited.
}

\begin{abstract}
It was tried to prepare composite particles made of polymer and two kinds of solid powders by forming Pickering emulsion followed by the drying-in-liquid method and to investigate how the stepwise addition of solid powders affected the contained ratio and adhesion ratio of solid powders and the structure of composite particles. Limonene oil dissolving expanded polystyrene and ethylene glycol were adopted as the dispersed phase and the continuous phase, respectively. Magnetite and titanium dioxide were used as solid powders. Magnetite was added before or after formation of the $(\mathrm{O} / \mathrm{W})$ dispersion. Titanium dioxide was added at the various elapsed times from addition of magnetite. Titanium dioxide adhered only on the surface of composite particles irrespective of addition time. At the earlier addition of both solid powders, the surface-covering type composite particles were prepared. At the latter addition of titanium dioxide, a part of magnetite adhered on the surface and the remainder was dispersed into composite particle.
\end{abstract}

Keywords: Composite Particles; Pickering Emulsion; Drying-In-Liquid Method; Liquid-Liquid Dispersion; Magnetite; Titanium Dioxide

\section{Introduction}

Many kinds of composite particles made of polymer and solid powders have been prepared by using the dispersion methods, namely, the suspension polymerization method [1-6], the miniemulsion polymerization method $[7,8]$, the dispersion polymerization method [9], the soap free emulsion polymerization method $[10,11]$ and the drying-in-liquid method [12-16] and so on. Also, there are many papers in which various interesting composite particles have been prepared by using the Pickering emulsion [17-20]. These composite particles have many excellent characteristics different from one of each component. For example, a lot of properties, such as electric conductivity, thermal conductivity, magnetic force, mechanical strength, dispersibility in the solvent, affinity for other materials and so on, can be added to polymer materials or solid powders. It is well known that these proper-

"Corresponding author. ties are strongly dependent on the physical properties of solid powders and polymers, the structure and morphology of composite particles and the content ratio of solid powders in the matrix polymers.

The present authors [1-16] have prepared various composite particles by utilizing the liquid-liquid dispersion followed by the suspension polymerization process, the miniemulsion polymerization process and the drying-in-liquid process, in which solid powders were added into the dispersion acted as a stabilizer and a component of composite particles. It was found that the physical properties of solid powders significantly affected the morphology and structure of composite particle. In particular, affinity of solid powders to the liquids was concerned, in other words, wettability of solid powder to the interface between the continuous and the dispersed phase, controls the structures of composite particles such as the surface-covering type and the inner-dispersed type. In the preparation methods stated just above, first, it is neces- 
sary for solid powders to adhere on the interface between the dispersed and the continuous phase. If affinity of solid powders to the interface is appropriate, solid powders should act as a stabilizer to prepare the surfacecovering type composite particles. Also, if affinity of solid powders is more hydrophobic, solid powders may cause the droplets to coalesce with each other to prepare coagulum and/or the inner-dispersed type composite particles.

Accordingly, if a few kinds of solid powders with different affinity are added into the liquid-liquid dispersion, it may be considered that the dispersing behavior of dispersed droplets and the structure of composite particles have to be affected by the addition time of solid powders.

However, there are not few works which have investigated the effect of addition of two kinds of solid powders.

In this study, in order to investigate the effect of addition of two kinds of solid powders, magnetite and titanium dioxide were adopted and added into the liquid-liquid dispersion. It was tried to prepare composite particles by forming Pickering emulsion followed by the drying-in-liquid method, in which the addition time of solid powders was mainly changed. The purpose of this study is to investigate how the addition time of solid powders affects the contained ratio and adhesion ratio of solid powders, the adhesion feature of solid powders on the surface of composite particles and the dispersing feature of solid powders in the matrix polymer of composite particles.

\section{Experimental}

\subsection{Materials}

Materials used to prepare composite particles were as follows: (R)- $(+)$ Limonene oil (Tokyo Chemical Industry Co., Ltd., Tokyo, Japan) as the solvent of wasted expanded polystyrene (EPS), Ethylene glycol as the continuous phase (Tokyo Chemical Industry Co., Ltd., Tokyo, Japan), Magnetite (mean diameter $300 \mathrm{~nm}$ ) and Titanium dioxide (mean diameter $210 \mathrm{~nm}$ ) powder (Tokyo Chemical Industry Co., Ltd., Tokyo, Japan).

\subsection{Experimental Apparatus}

Figure 1 shows the schematic diagram of experimental apparatus. A separable flask with a flat bottom was used as the reactor to prepare composite particles. Four baffles made of aluminum plate with a width of $1 \mathrm{~cm}$ and a length of $6 \mathrm{~cm}$ were installed on the inside wall of the reactor. An impeller used in preparing composite particles was a six-blade disc turbine with a diameter of 5.4 $\mathrm{cm}$ and a width of $1.5 \mathrm{~cm}$ as shown in Figure 1, which was fixed at one-third of the liquid height from the reactor bottom. The reactor was set in the mantle heater to keep temperature of the dispersion constant. A thermocouple was inserted in the reactor to control temperature of the dispersion.

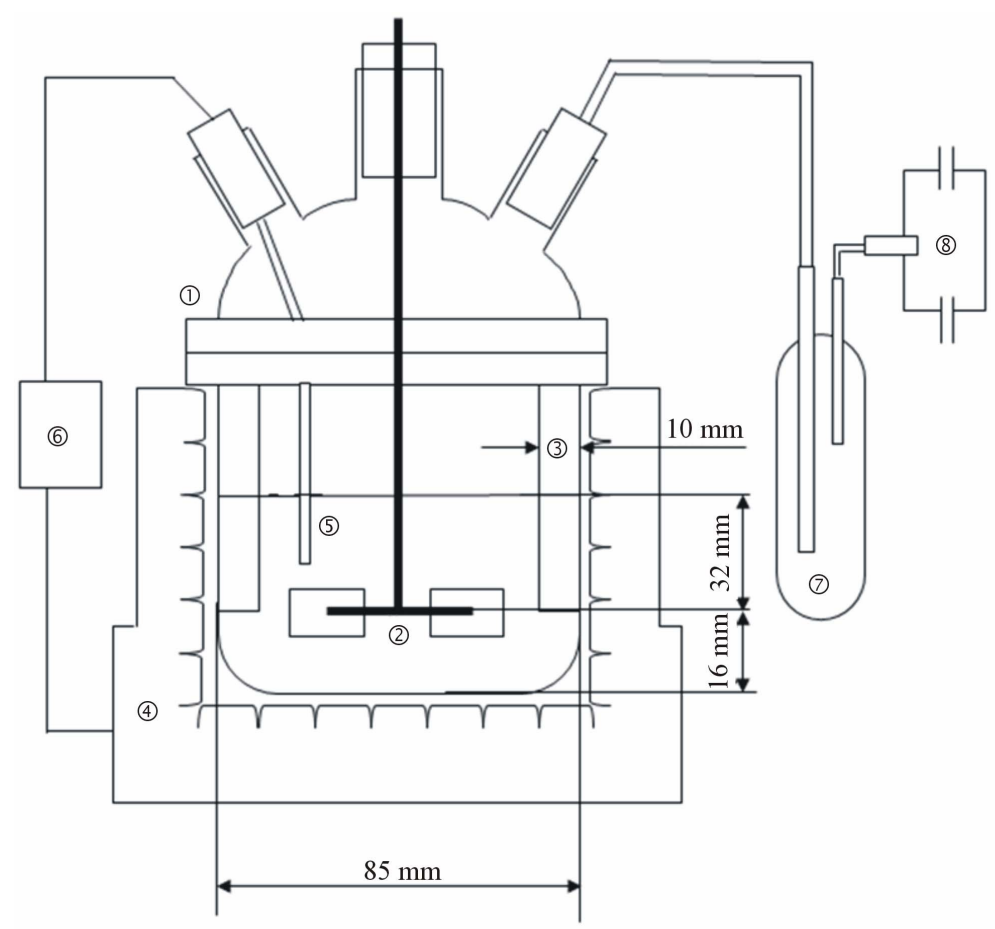

(1) Separable Flask

(2) Impeller

(3) Baffle

(4) Mantle Heater

(5) Thermocouple

(6) Temperature Controller

(7) Cold Trap

(8) Aspirator

Figure 1. Schematic diagram of experimental apparatus. 


\subsection{Liquid-Liquid Dispersion Experiment}

Prior to preparation of composite particles, the liquidliquid dispersion experiment was conducted as follows. Magnetite and titanium dioxide were added into the test tube in which Limonene oil dissolving EPS and ethylene glycol were poured beforehand. This test tube was shaked for two min by the test tube shaker and then, it was observed where both solid powders were dispersed. Also, it was investigated how these solid powders affected stability of the liquid-liquid dispersion. In order to prepare composite particles, solid powders have to adhere on the surface of dispersed droplets and make the liquid-liquid dispersion stable.

\subsection{Preparing of Composite Particles}

Figure 2 shows the flow chart for preparing composite particles. In brief, Limonene oil (boiling point $178^{\circ} \mathrm{C}$ ) dissolving EPS of given weight was the dispersed phase and ethylene glycol (boiling point $198^{\circ} \mathrm{C}$ ) was the continuous phase. The dispersed phase was stirred in the continuous phase with the impeller for ten min to form the $(\mathrm{O} / \mathrm{W})$ dispersion. Magnetite was added two times into the $(\mathrm{O} / \mathrm{W})$ dispersion in slurry as shown in Figure 2 , namely the first time is the starting point $(t=0)$ to form the $(\mathrm{O} / \mathrm{W})$ dispersion and the second time is the end point $(t=10 \mathrm{~min})$ of formation of the $(\mathrm{O} / \mathrm{W})$ dispersion. Here, the end point of formation of the $(\mathrm{O} / \mathrm{W})$ dispersion is the starting point of the drying-in-liquid process. On the other hand, when magnetite was added at $t=0$, titanium dioxide was added between $t=0$ and $t=20 \mathrm{~min}$ and when magnetite was added at $t=10 \mathrm{~min}$, titanium dioxide was added between $t=10 \mathrm{~min}$ and $25 \mathrm{~min}$. In the former case of addition of titanium dioxide, the effect of solid powders on the dispersing behaviors of liquid droplets at both the formation process of the $(\mathrm{O} / \mathrm{W})$ dispersion and the drying-in-liquid process was investigated. In the latter case of addition of titanium dioxide, the effect of solid powders on the dispersing behaviors of liquid droplets at the drying-in-liquid process was mainly investigated. The drying-in-liquid process was continued for $3.5 \mathrm{~h}$ at $100^{\circ} \mathrm{C}$ and then, composite particles were prepared. The experimental conditions are shown in Table 1.

\subsection{Characterization}

\subsubsection{Estimation of Effect of Solid Powders on Stability of (O/W) Dispersion}

Pickering emulsion was formed with stirring for forty min after adding solid powders of given weight. Then, Pickering emulsion was settled down and stability of the $(\mathrm{O} / \mathrm{W})$ dispersion was observed by measuring the height of the dispersion at the constant time interval. Here, the

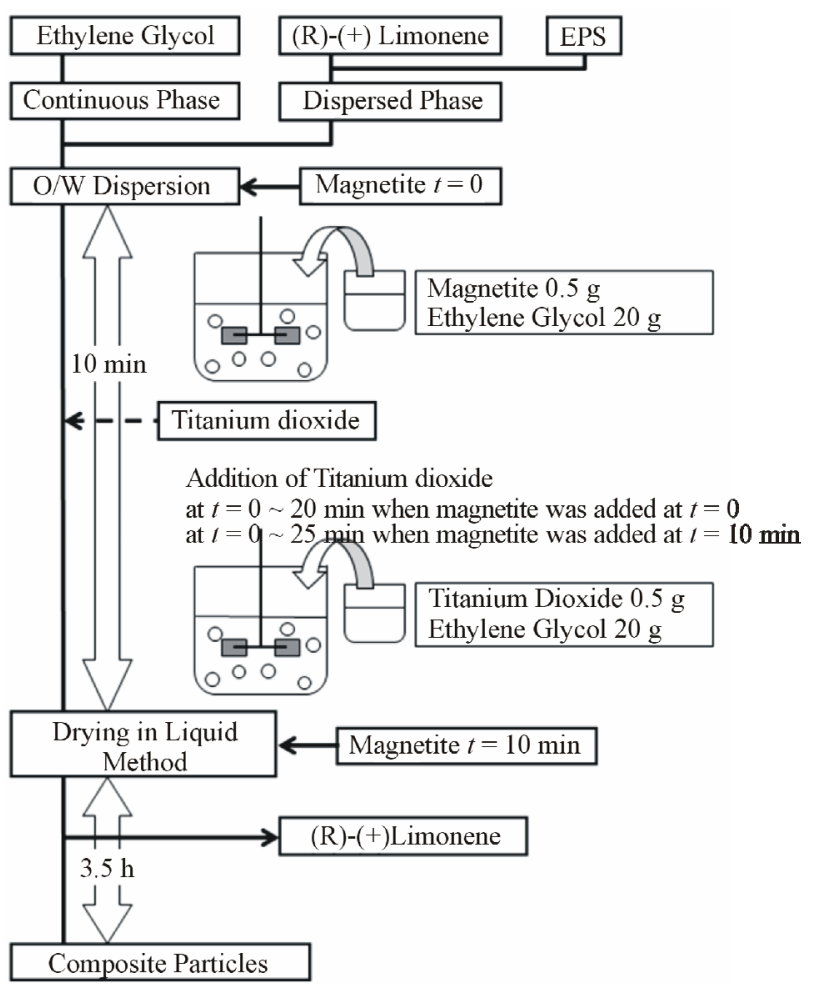

Figure 2. Flow chart for preparing composite particles.

Table 1. Experimental conditions.

\begin{tabular}{|c|c|}
\hline \multicolumn{2}{|l|}{ Dispersed Phase } \\
\hline \multicolumn{2}{|c|}{ (Waste Plastics (EPS) $8.4 \mathrm{~g},(\mathrm{R})-(+)$ Limonene $16.6 \mathrm{~g}$ ) } \\
\hline \multicolumn{2}{|l|}{ Continuous Phase } \\
\hline Ethylene Glycol & $280 \mathrm{~g}$ \\
\hline \multicolumn{2}{|l|}{ Solid Powder } \\
\hline Magnetite & $0.5 \mathrm{~g} / 20 \mathrm{~g}$ - Ethylene Glyco \\
\hline Titanium Dioxide & $0.5 \mathrm{~g} / 20 \mathrm{~g}$ - Ethylene Glycol \\
\hline \multicolumn{2}{|l|}{ Formation of $(\mathrm{O} / \mathrm{W})$ Dispersion } \\
\hline Impeller Speed & $4.16 \mathrm{~s}^{-1}$ \\
\hline Stirring Time & $10 \mathrm{~min}$ \\
\hline Temperature & $40^{\circ} \mathrm{C}$ \\
\hline \multicolumn{2}{|l|}{ Drying-in-Liquid Operation } \\
\hline Impeller Speed & $4.16 \mathrm{~s}^{-1}$ \\
\hline Time & $3.5 \mathrm{~h}$ \\
\hline Temperature & $100^{\circ} \mathrm{C}$ \\
\hline
\end{tabular}

contact angles of magnetite and titanium dioxide to the interface between the dispersed and the continuous phase are $64^{\circ}$ and $73^{\circ}$, respectively $[2,3,6]$.

\subsubsection{Observation of Composite Particles}

The surface and inner structure of a composite particle 
were observed by scanning electron microscope (SEM) (JSM-5800, JEOL Ltd., Tokyo, Japan). The adhesion feature of solid powders on the surface and the dispersing feature in the matrix polymer of a composite particle were observed by electron probe microanalyser (EPMA8705, Shimadzu Corp., Kyoto, Japan), respectively.

\subsubsection{Measurement of Amount of Solid Powders Contained}

Composite particles of $10 \mathrm{mg}$ were set in a melting pot and heated to remove polystyrene by incineration. Changes of magnetite to hematite and anatase type titanium dioxide to rutile type by this incineration were estimated by x-ray diffraction. After this operation, remnants in the pot were weighed and dissolved in hydrochloric acid of $10 \mathrm{~cm}^{3}$. The concentration of magnetite was estimated by measuring the absorption degree of this hydrochloric acid solution with the spectrophotometer (UV-160A, Shimadzu Corp., Kyoto, Japan). For this measurement, the correlation curve between the concentration of hematite and the absorption degree was prepared beforehand. By this measurement, the weight of magnetite contained was estimated. On the other hand, the contained weight of titanium dioxide was estimated from both the measured weights of composite particles and magnetite. The contained ratios of magnetite and titanium dioxide $\left(W_{c M}, W_{c T}\right)$ were defined as follows.

$$
W_{c M} \text { or } W_{c T}=\frac{\text { weight of solid powder contained }}{\text { weight of composite particles }}
$$

\subsubsection{Measurement of Weight of Solid Powder Adhered on the Surface of Composite Particles}

Adhesion weight of solid powders on the surface of composite particles was measured by the following procedure. Namely, composite particles of $10 \mathrm{mg}$ was poured in hydrochloric acid of $10 \mathrm{~cm}^{3}$ and magnetite on the surface was dissolved. The weight of magnetite adhered on the surface was estimated from the correlation curve described just above. Accordingly, the weight of titanium dioxide adhered on the surface was estimated from the contained ratios of both solid powders and the adhesion weight of magnetite. Thus, the adhesion ratios $\left(W_{a M}, W_{a T}\right)$ of both solid powders adhered on the surface of composite particles were defined as follows.

$$
W_{a M} \text { or } W_{a T}=\frac{\text { weight of solid powder adhered on the surface }}{\text { weight of composite particles }}(2)
$$

\section{Results and Discussion}

\subsection{Effect of Solid Powders on Stability of (O/W) Dispersion}

Figure 3 shows the results of observation of the dispers- ing feature of the $(\mathrm{O} / \mathrm{W})$ dispersion before and after shaking together with the transient height of the dispersion.

From this result, it is found that both powders are in the continuous phase due to gravity before shaking, but a part of each solid powder is in both the dispersed phase and the continuous phase after shaking. Furthermore, after shaking, as the height of the dispersed phase becomes higher than that before shaking and the height of the continuous phase becomes lower than that before shaking, it may be considered that the $(\mathrm{O} / \mathrm{W})$ dispersion is formed in the upper region as shown in an illustration of Figure 3. Also, as the height of $(\mathrm{O} / \mathrm{W})$ dispersion is kept constant for $5 \mathrm{~h}$, the oil droplets have to be stabilized by the solid powders adhered on the surface of droplets. Then, the height of $(\mathrm{O} / \mathrm{W})$ dispersion gradually decreases due to breaking of emulsion. In order to prepare the surface-covering type composite particles which polymer particle is coated with solid powders, it is necessary for the solid powders to adhere on the surface of oil droplets. Also, in order to prepare the inner dispersed type composite particles which solid powders are dispersed into polymer particle, it is necessary for the solid powders to be dispersed into the liquid droplets.

\subsection{Contained Ratio and Adhesion Ratio}

Figure 4 shows the dependence of the contained ratios of magnetite $\left(W_{c M}\right)$ and titanium dioxide $\left(W_{c T}\right)$ on the addition time of titanium dioxide, where magnetite was added at $t=0$. With the addition time of titanium dioxide, the contained ratios of both solid powders increase, become maximum at $t=10 \mathrm{~min}$ and then, decrease. From this result, it is found that the contained ratios of both solid


Figure 3. Observation of $(\mathrm{O} / \mathrm{W})$ dispersion and transient height of dispersion. 
powders are almost the same values irrespective of the addition time of titanium dioxide. As, at the earlier stage of formation of the $(\mathrm{O} / \mathrm{W})$ dispersion, the interfacial area of oil droplets is relatively small, the contained ratios of both solid powders may become low. As the interfacial area of oil droplets becomes larger during formation of the $(\mathrm{O} / \mathrm{W})$ dispersion, the contained ratios of both solid powders may be increased. However, as the interfacial area becomes maximum just before starting of the drying-in-liquid process and has to inevitably decrease due to removal of solvent thereafter, the contained ratios may become maximum and then, decrease. As the maximum values $(5.1 \%)$ of the contained ratios are very close to these $(5.9 \%)$ based on the feed weights of solid powders, it is considered that almost solid powders have to be dispersed into oil droplets and/or adhere on the surface of liquid droplets. When the drying-in-liquid process is finished, the interfacial area of the $(\mathrm{O} / \mathrm{W})$ dispersion at $\mathrm{t}=10 \mathrm{~min}$ has to be reduced to $42 \%$ of that at the initial $(\mathrm{O} / \mathrm{W})$ dispersion. Solid powders adhered on the surface of oil droplets may be removed by this shrinkage of the surface area.

Figure 5 shows the dependence of the adhesion ratios of magnetite and titanium dioxide on the addition time of titanium dioxide together with the contained ratios, where magnetite was added at $t=0$. The adhesion ratios show the same change profile as the contained ratios. Namely, with the addition time, the adhesion ratio increases, becomes maximum at $t=10$ and then, decreases. Here, the values of $\left(W_{C M}-W_{a M}\right)$ may be considered to be the weight dispersed into composite particles. Accord-

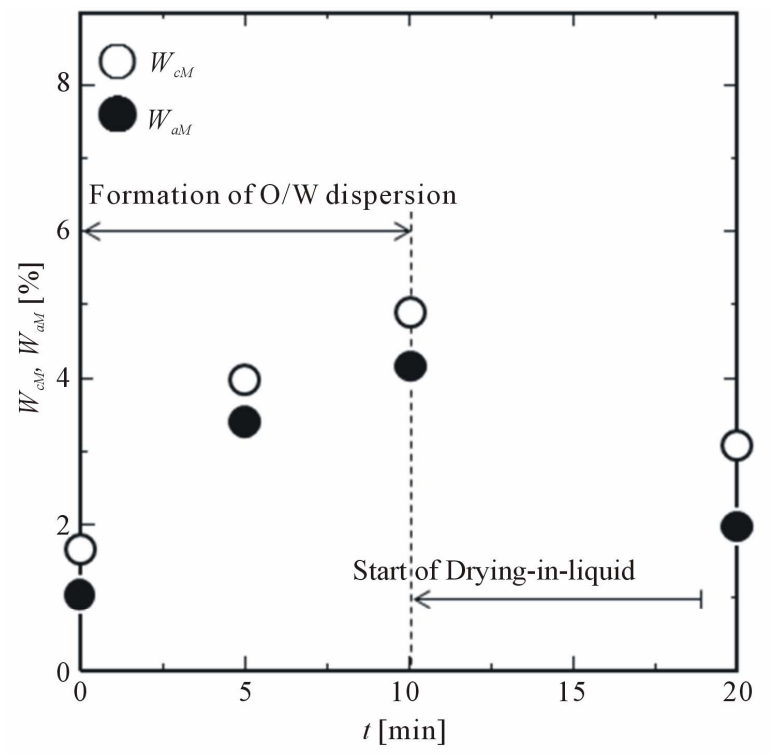

(a) ingly, it is interesting to note that the weight of magnetite dispersed into composite particles increases with the addition time of titanium dioxide. On the other hand, the adhesion ratios of titanium dioxide become equal to the contained ratios. This result may mean that titanium dioxide almost adheres on the surface of oil droplets and may not be dispersed into composite particles. As magnetite is more hydrophobic than titanium dioxide, the later the addition of titanium dioxide, the more magnetite may be dispersed into the oil droplets.



Figure 4. Dependence of contained ratios of both solid powders on addition time of titanium dioxide (magnetite was added at $t=0$ ).



(b)

Figure 5. Dependence of adhesion ratios and contained ratios of both solid powders on addition time of titanium dioxide (magnetite was added at $t=0$ ). 
Figure 6 shows the dependence of the contained ratios of both solid powders on the addition time of titanium dioxide, where magnetite is added at $t=10 \mathrm{~min}$. Addition of titanium dioxide at $t=10$ min means that both solid powders are added at the same time and the $(\mathrm{O} / \mathrm{W})$ dispersion is formed without any stabilizer. Also, the drying-in-liquid process is started at $t=10 \mathrm{~min}$. From this result, the contained ratios of both solid powders are found to be almost equal to each other. Furthermore, with the addition time of titanium dioxide, the contained ratios decrease because of disturbance of adhesion of solid powders due to removal of solvent from the oil droplets and decrease in the interfacial area. Also, as the interface may change from liquid to solid at the latter stage of the drying-in-liquid process, it may become hard for solid powders to adhere on the interface.

Figure 7 shows the dependence of the adhesion ratios of magnetite (a) and titanium dioxide (b) on the addition time of titanium dioxide together with the contained ratio, where magnetite is added at $t=10 \mathrm{~min}$. It is found that the value $\left(W_{C M}-W_{a M}\right)$ of weight of magnetite dispersed into composite particles gradually decreases with the addition time of titanium dioxide and becomes constant (Ca. $4.0 \mathrm{wt} \%$ ). On the other hand, the adhesion ratio of titanium dioxide is slightly smaller than the contained ratio. This result may mean that the weight of titanium dioxide dispersed into composite particles is very low.

Figure 8 shows the SEM photographs of composite particles prepared at $t=0 \mathrm{~min}$ for magnetite and $t=20$ min for titanium dioxide (a) and at $t=10 \mathrm{~min}$ for magnetite and $t=25 \mathrm{~min}$ for titanium dioxide (b). It is found

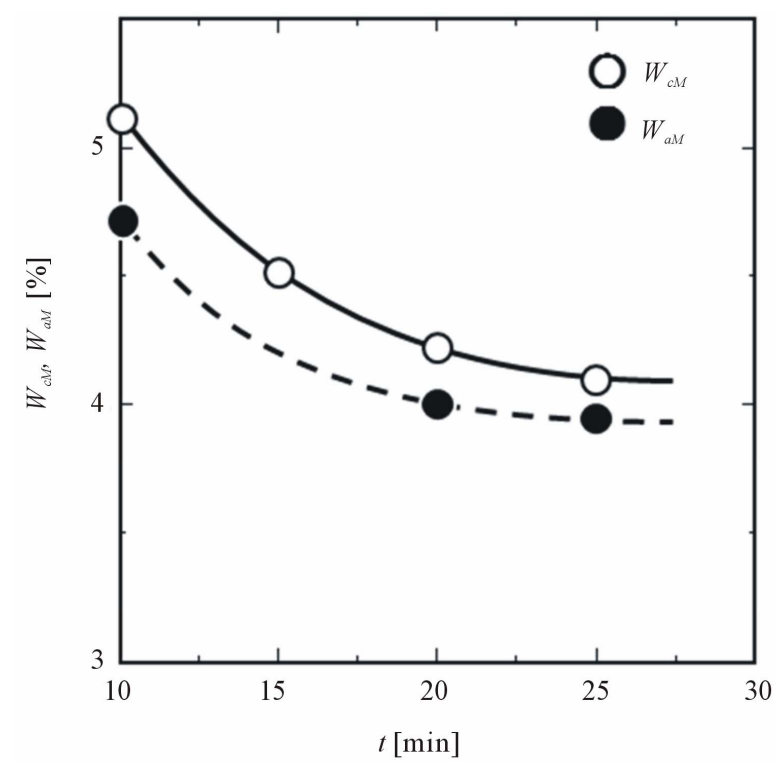

(a) that composite particles prepared under all the experimental conditions adopted in this study are spherical and the surface of a composite particle becomes rough at (a) and smooth at (b), respectively. In the case of addition ( $t$ $=0$ for magnetite) before the drying-in-liquid process, the layer of solid powders adhered on the surface of oil droplets may be shrunk due to removal of solvent. As a result, it may be considered that the surface of a composite particle becomes rough as shown in Figure 8(a). On the other hand, the adhesion layer of solid powder

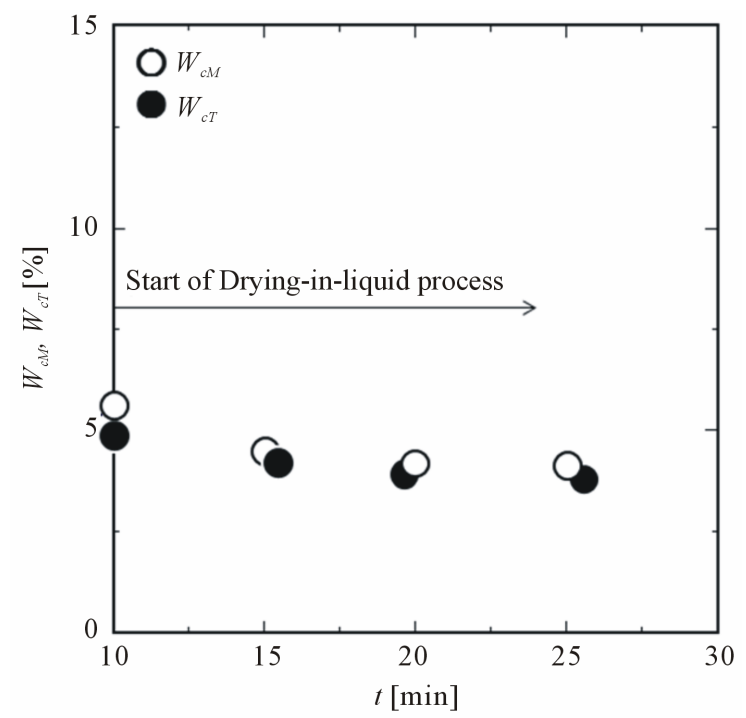

Figure 6. Dependence of contained ratios of both solid powders on addition time of titanium dioxide (magnetite was added at $t=10 \mathrm{~min}$ ).



(b)

Figure 7. Dependence of adhesion ratios and contained ratios of both solid powders on addition time of titanium dioxide (magnetite was added at $t=10 \mathrm{~min}$ ). 

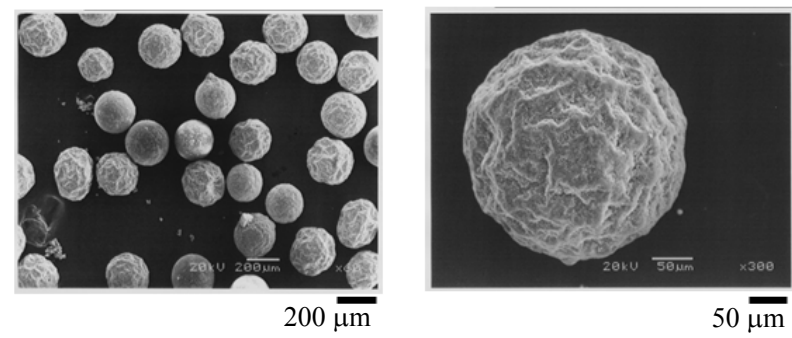

(a)
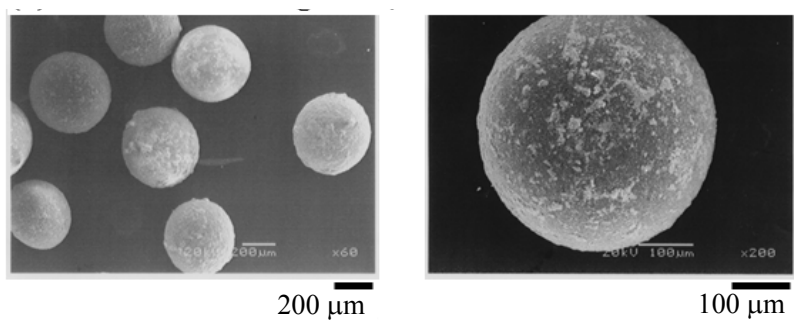

(b)

Figure 8. SEM photographs of composite particles. (a) $t=0$ min for magnetite, $t=20$ min for titanium dioxide; (b) $t=10$ min for magnetite, $t=25$ min for titanium dioxide.

adhered during the drying-in-liquid process may not be shrunk significantly because of smaller shrinkage of interfacial area.

Figure 9 shows the SEM photograph and the x-ray images of cross section of composite particle prepared at $t=0$ for magnetite and titanium dioxide. As the $(\mathrm{O} / \mathrm{W})$ dispersion is stabilized by addition of both solid powders at the same time, both solid powders are found to almost adhere on the surface of composite particle, but a part of magnetite is dispersed into composite particle.

Figure 10 shows the SEM photographs and the $x$-ray images of cross sections of composite particles prepared at $t=10 \mathrm{~min}$ for magnetite and $20 \mathrm{~min}$ for titanium dioxide. For comparison, the $\mathrm{x}$-ray images of cross sections of composite particles prepared at $t=0$ for magnetite and titanium dioxide are shown in Figure 10. The different phenomena due to the addition time can not be observed from the SEM photographs.

From the $\mathrm{x}$-ray images, it is found that more magnetite is dispersed into composite particles by the latter addition of titanium dioxide and composite particles with both the surface-covering and the inner dispersed structure are able to be prepared.

Also, from the x-ray images (TiK $\alpha)$, it is found that almost titanium dioxide adhere only on the surface of composite particles. Furthermore, titanium dioxide is found to act as a stabilizer and to form the adhesion layer together with magnetite.

\section{Conclusions}

It was tried to prepare composite particles by changing


Figure 9. SEM photographs and $x$-ray images of cross section of composite particles $(t=0$ for magnetite and titanium dioxide).

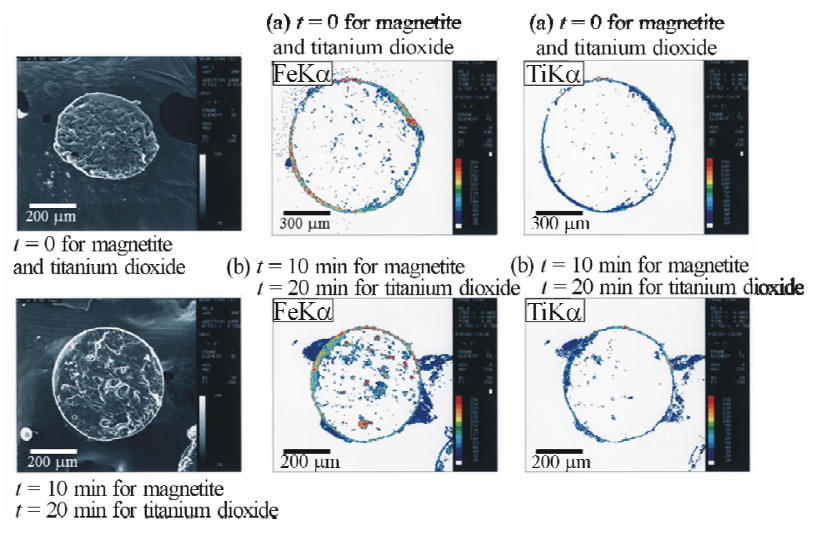

Figure 10. SEM photographs and $x$-ray images of cross sections of composite particle prepared at $t=10$ for magnetite and $t=20 \mathrm{~min}$ for titanium dioxide.

the addition times of magnetite and titanium dioxide and the following results were obtained.

1. Composite particles prepared under the experimental conditions adopted in this study were spherical.

2. More hydrophilic titanium dioxide almost adhered on the surface of composite particles, and more hydrophobic magnetite adhered on the surface, but a part of them was dispersed into composite particles.

3. The later the addition of titanium dioxide, the more magnetite was dispersed into composite particles.

4. The structure of composite particles, namely the surface-covering type and inner-dispersed type, was able to be controlled by the addition time of more hydrophilic solid powder.

\section{REFERENCES}

[1] E. O'shima and M. Tanaka, "Effect of Solid Powders on Stability of Suspension Polymerization of Styrene," $\mathrm{Ka}$ gaku Kogaku Ronbunshu, Vol. 8, No. 2, 1982, pp. 188193. http://dx.doi.org/10.1252/kakoronbunshu. 8.188

[2] M. Tanaka and K. Hayashi, "Preparation of Polystyrene Particles Coated with Ferrite Powder by Suspension Polymerization," Kagaku Kogaku Ronbunshu, Vol. 15, No. 6, 1989, pp. 1144-1152. http://dx.doi.org/10.1252/kakoronbunshu.15.1144

[3] M. Tanaka and K. Hayashi, "Preparation of Polymer Particles Covered with Ferrite Powder by Suspension Polymerization: Effect of Wettability of Powder on Com- 
posite Particle Size Distribution," Journal of Materials Science, Vol. 25, 1990, pp. 987-991.

[4] M. Tanaka and K. Hayashi, "Preparation of Polystyrene Particles with Carbon Black Covered Uniformly with Ferrite Powder by Suspension Polymerization," The Japan Society of Colour Material, Vol. 63, No. 6, 1990, pp. 321329.

[5] N. Saito, K. Hosogai, I. Kimura and M. Tanaka, "Effect of Pigments on Size Distribution of Colored Polystyrene Particles produced by Suspension Polymerization," the Japan Society of Colour Material, Vol. 64, No. 8, 1991, pp. 493-501.

[6] M. Tanaka, A. Saito, K. Hosogai and I. Kimura, "Preparation of Fine Polymer Particles Coated Uniformly with Magnetite Powder by Suspension Polymerization," Kagaku Kogaku Ronbunshu, Vol. 18, No. 3, 1992, pp. 330337. http://dx.doi.org/10.1252/kakoronbunshu.18.330

[7] S. Kobayashi, Y. Taguchi and M. Tanaka, "Preparation of Nanospheres Containing Dye by Mini Emulsion Polymerization," The Japan Society of Colour Material, Vol. 78, No. 6, 2005, pp. 260-264.

[8] I. Shindo, Y. Taguchi and M. Tanaka, "Preparation of White-Colored-Composite Nanoparticles by Miniemulsion Polymerization," The Japan Society of Colour Material, Vol. 78, No. 10, 2005, pp. 468-472.

[9] N. Saito, Y. Taguchi and M. Tanaka, "Preparation of Colored Microspheres by Dispersion Polymerization," the Japan Society of Colour Material, Vol. 71, No. 4, 1998, pp. 232-238.

[10] N. Saito, I. Kimura and M. Tanaka, "Effect of the Addition of Water-Soluble Polymeric Species on the Encapsulation of Pigments by Soap-Free Emulsion Polymerization," The Japan Society of Colour Material, Vol. 68, No. 9, 1995, pp. 535-541.

[11] N. Saito, Y. Taguchi and M. Tanaka, "Effect of Addition Method of Surfactant on Encapsulation of Nano-Particles by Soap-Free Emulsion Polymerization," The Japan Society of Colour Material, Vol. 77, No. 7, 2004, pp. 303308.

[12] M. Tanaka, Y. Taguchi and Y. Iguchi, "Preparation of Composite Particles Composed of Waste Polymer and Solid Powder Using Semi-Chemical Recycle Method," Kagaku Kogaku Ronbunshu, Vol. 24, No. 3, 1998, pp. 509-511. http://dx.doi.org/10.1252/kakoronbunshu.24.509
[13] Y. Taguchi and M. Tanaka, "Preparation of Microcapsules Composed of Waste-Expanded Polystyrene and Paper Fiber by Semichemical Recycle," Journal of Applied Polymer Science, Vol. 80, 2001, pp. 2662-2669. http://dx.doi.org/10.1002/app.1379

[14] Y. Taguchi and M. Tanaka, "Preparation of Composite Particles Composed of Two Kinds of Solid Powders and Waste Polymer by Semi-Chemical Recycle Method," Journal of Chemical Engineering of Japan, Vol. 34, No. 9, 2001, pp. 1177-1181. http://dx.doi.org/10.1252/jcej.34.1177

[15] Y. Taguchi and M. Tanaka, "Preparation of Composite Particles Made from Solid Powders and Wasted Plastics by Semichemical Recycle Method," Journal of Applied Polymer Science, Vol. 88, 2003, pp. 483-488. http://dx.doi.org/10.1002/app.11920

[16] M. Tanaka, Y. Taguchi, N. Sawatari and N. Saito, "Preparation of Composite Particles Coated with Two Kinds of Solid Powders by Semi-Chemical Recycle Method," Journal of Materials Science, Vol. 41, 2006, pp. 4215-4220. http://dx.doi.org/10.1007/s10853-006-6273-9

[17] D. J. Voorn, W. Ming and A. M. van Herk, "PolymerClay Nanocomposite Latex Particles by Inverse Pickering Emulsion Polymerization Stabilized with Hydrophobic Montmorillonite Platelets," Macromolecules, Vol. 39, No. 6, 2006, pp. 2137-2143. http://dx.doi.org/10.1021/ma052539t

[18] H. Y. Wen, G. Gao, Z. R. Han and F. Q. Liu, "MagnetiteCoated Polystyrene Hybrid Microspheres Prepared by Miniemulsion Polymerization," Polymer International, Vol. 57, No. 4, 2008, pp. 584-591. http://dx.doi.org/10.1002/pi.2287

[19] Q. Gao, C. Wang, H. Liu, C. Wang, X. Liu and Z. Tong, "Suspension Polymerization Based on Inverse Pickering Emulsion Droplets for Thermo-Sensitive Hybrid Microcapsules with Tunable Supracolloidal Structures," Polymer, Vol. 50, No. 12, 2009, pp. 2587-2594. http://dx.doi.org/10.1016/j.polymer.2009.03.049

[20] K. Zhang, W. Wu, H. Meng, K. Guo and J. F. Chen, "Pickering Emulsion Polymerization: Preparation of Polystyrene/Nano-SiO2 Composite Microspheres with CoreShell," Powder Technology, Vol. 109, No. 3, 2009, pp. 393-400. http://dx.doi.org/10.1016/j.powtec.2008.08.022 